\title{
New Approaches to Designing Production System Structures
}

\author{
Rudy Vladimír ${ }^{1}$, Peter Malega ${ }^{2 *}$, Juraj Kováč ${ }^{3}$
}

\author{
'Technical University of Košice, Faculty of Mechanical Engineering, Institute of Management, Industrial and Digital Engineering, Park Komenskeho 9, \\ 04200 Košice, Slovakia \\ ${ }^{2}$ Technical University of Košice, Faculty of Mechanical Engineering, Institute of Management, Industrial and Digital Engineering, Park Komenskeho 9, \\ 04200 Košice, Slovakia
}

${ }^{3}$ Technical University of Košice, Faculty of Mechanical Engineering, Institute of Management, Industrial and Digital Engineering, Park Komenskeho 9 , 04200 Košice, Slovakia

\begin{abstract}
This article is oriented on the new approaches to designing production system structures. It is divided into four main sections. First main section deals with philosophical aspects of production structure designs and their complexity. Second main section is about new approaches to designing customer-oriented productions and there are summarized technologies for viewing virtual scenes. Third main section treats with innovative process design in mechanical production and you can find their pillars of customer oriented production systems of the future. Fourth main section is oriented on production systems supported by design using virtual reality.
\end{abstract}

Keywords: production structure; production system; customer-oriented production; virtual reality; design; systems of the future.

\section{Introduction}

EEngineering production design requires a system solution for a set of structural, technological, spatial and organizational factors resulting in the design of an optimal manufacturing configuration. The goal is the functional integration of people, information, production technology, materials and energy to prevent wasting these resources and to achieve high productivity. The efficiency of operation depends on the level of mutual synchronization, the ability to predict and eliminate adverse effects of these factors on the production characteristics of the production system. Therefore, the role of design activity is to design and, in the form of design documentation, to process the production configuration that can be executed under optimal financial conditions in the required space and time, capable to meet time-limited market demands. $[1,5]$

The final design, taking into account the mutual synergy of these factors and guaranteeing the consistency of designed ideas with the achieved results, leads in practice to the complexity and variability of possible solutions. Capability of reconfiguration or building new innovative productions is, therefore, one of the most complex tasks in the company life cycle. It requires the application of adequate computer, information and software support for modern CAx systems capable to apply standardized design procedures and to modify configurations from "proven" designs. [2]

A production systems new type's structures development thus requires answers to other questions supporting integrity, equivalency and synergy of functions and activity. They become determining factors for simple and unambiguous integrating into production-logistic chain. [19] One opportunity to optimize production system 
design is segmentation of the manufacturing enterprise into small, flexible and decentralized production units. A segmented production system resembles a hybrid form of centralized and decentralized organizational structure. Segments are organizational sub-units of the production system with dedication to integrated processes. [20]

Hence, manufacturing systems must be able to smoothly and rapidly adapt to the fast evolving market dynamics. Different system paradigms have been proposed to efficiently and effectively adapt to the market dynamics, e.g. flexibility and reconfigurability. These paradigms implement specific technological features such as modularity and changeability, to enable modifications of the production systems in response to the needs of the market. Moreover, the concept of co-evolution of products, processes and production systems has been identified as a key factor in companies to manage strategically and operationally the propagation of engineering changes, and to gain competitive advantage from the resulting market and regulatory dynamics. [21]

\section{Philosophical aspects of production structure designs and their complexity}

Innovations in project activities require special knowledge and appropriate methods, procedures and tools. An important role is played by theoretical sciences. The development of engineering work is supported by several engineering disciplines. Design Science (Design Theory, Design Philosophy) is important because it contains a set of logically clustered knowledge about solutions generated by engineering activities. Designing is a complex area of theories, methods and information, including a broad field of engineering activity. The knowledge base of design team members can be divided into [3]:

$\checkmark$ General and special knowledge of technical systems and processes, including the manner of their expression, characteristics and quality, structures and principles of their development.

$\checkmark$ General and special knowledge of engineering design, its structure, features, characteristics and management.

$\checkmark$ Special, detailed, design-necessary knowledge of the technical, technological, economic, organizational and control nature of the aspect of design.

$\checkmark$ Managerial skills in the field of design management and teamwork.
Designing today's manufacturing systems requires a comprehensive analysis of their activities in real space and time. Only this approach is a guarantee of identification, optimization, or elimination of design deficiencies before their future physical implementation. It is necessary to take into account the philosophical aspects of technological innovations, modeling, examples and studies of successful reference solutions, financial support and material provision for innovative changes, multi-purpose and purposeoriented designs for the synthesis of technological innovations, etc. The frame methodology of application designated for the assembly of the production structure model takes place in four stages:

1. Creation of knowledge base and its analysis (in accordance with customer requirements).

2. 20 / 30 variant modeling - spatial optimization of the system's structure.

3. Optimal production structure - functional simulation of the virtual production model.

4. Production of design documentation, GIS modification of the production model and its implementation.

Concepts of new production systems are currently designed as the systems of new generation. The aim of such solutions is to increase productivity without losing flexibility, shortening production time, increasing the quality and the value of products and services, and so on. They are modified as social and economic systems and place high demands on design, implementation and operation. The numerous papers in professional literature deal with their development.

Combination of software applications with hardware of 3D type beamers, cameras, 3D scanners, digitizers, etc., enables the future real image of the production system to be interpreted in virtual reality and by that [4]:

$\checkmark$ it reveals critical deficiencies before the real system implementation,

$\checkmark$ simulates the functional activity of system elements, i.e. verifies dynamic properties of static objects (e.g. the course of technological processes, movement of workers, flow of material).

\section{New approaches to designing customer- oriented productions}

Design of today's complex structure of diverse manufacturing systems requires a comprehensive analysis of the activities involved in three spatial 
dimensions and in time. Only this approach is a guarantee of identification, optimization, or elimination of design deficiencies before they are physically implemented in the future.

Greater requirements for design activity need significant computer support, i.e. information and computer technologies, without which the high quality of design, greater variety of solutions, innovative flexibility as well as other attributes, are difficult to achieve. Current development enables these different approaches to be included in a single integrated system. Synchronous work in real and virtual environments brings a number of effects. Integrated procedures ensure that all actions applied to real physical models are transferred to parallel work with computer models that are subsequently presented in virtual environment. An important innovative method of designing production systems is simulation and its methods, techniques and tools. Managing simulation means $[6,8]$ :

$\checkmark$ a thorough analysis of CAE variants of generated structures and the complexity of their assessment as a result of a multidisciplinary solution,

$\checkmark$ searching and application of prototype, already existing knowledge databases enabling data re-use,

$\checkmark$ in combination with supportive process algorithm procedures, it enables the verification of the use of already approved analysis procedures, etc.

$\checkmark$ visualization of simulation results of the time cycle of simulated action in a specific environment.

$\checkmark$ the reliability and confidence of the reality of the results obtained and the possibility of online feedback on the development, or design status.

In the past, the concepts of creating production system configuration rested on the creation of two model types. The models were not integrated with one another or used together. The overview of the virtual reality technical means and technologies is shown in Fig. 1.

Models of virtual reality enable:

$\checkmark$ replacement of physical prototypes with virtual ones,

$\checkmark$ improvement and acceleration of the product development processes,

$\checkmark$ simulation of different development stages in virtual environment.

In virtual environment there are applied in engineering production $[9,11]$ :

$\checkmark$ Process planning (production layout, time analyses, technological preparation of production, product evaluation, cost analyses, etc.).

$\checkmark$ Replacing physical prototypes with virtual ones.

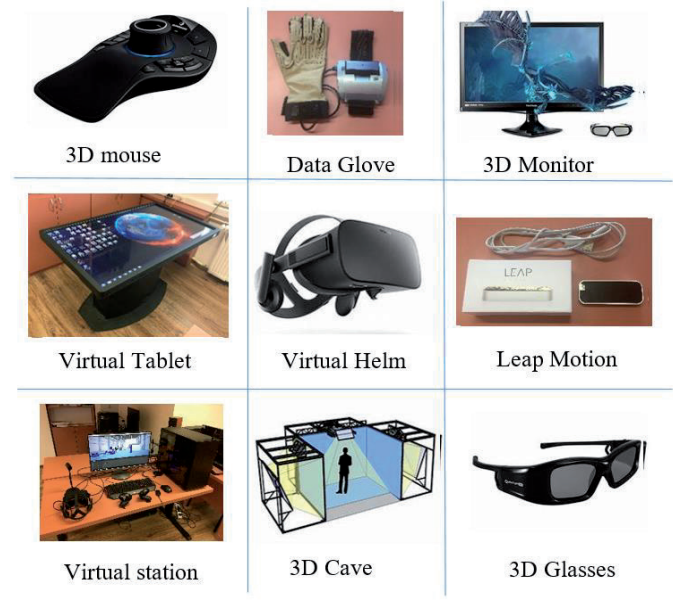

Fig. 1: Technologies for viewing virtual scenes [7].

$\checkmark$ Improving and accelerating the product development processes.

$\checkmark$ Simulating different development stages in virtual environment.

$\checkmark$ Processing details and validation (production and maintenance, welding, assembly procedures, cell and factory layouts, manufacturing operations, employee performance, etc.).

$\checkmark$ Modeling and resource simulation (material flow simulation, robotic cell type pre-specification, NC machining, virtual reality scenarios, ergonomic analyses, etc.).

$\checkmark$ Automation and Control (Control Logic, Programming, Robots).

The use of digital enterprise should improve economic and production indicators, namely by reducing the respective costs. Any small savings that will be gained during the planning stage will be multiplied in serial production, significantly increasing the return on investment into the system of digital enterprise.

The digital enterprise model allows for designing manufacturing procedures as well as technologies, including the insertion of a different degree of automation. It allows for running tests in virtual practice in which the physical properties of materials and specific production activities are programmed, as well as the assembly procedures in a particular workstation - including the preparation of tools in accordance with the worker's ergonomic requirements.

The designer is able to assemble the entire production hall in the software, to try the machine deployment, and to test the processes of in-house logistics, too. According to hitherto published analyses, all this results in cost savings, better resource utilization and material flow optimization, or spatial optimization of an adequate number of 
machines in the area.

The core of the digital enterprise virtual environment is represented by various modeling systems, including, e.g. CAD systems, computing and simulation systems as well as administrative applications. Contact with the outside world is maintained through three systems: the communication and information system and the data management system.

\section{Innovative process design in mechanical production}

From the basic approaches to development of engineering design point of view, design methodologies are developed as knowledge based engineering. This taking over by knowledge based engineering is manifested in expert systems and differences from the classic program systems in more than one feature.

In a competitive environment with the production volume changing dynamically having a permanent implementation of new production variants and technologies could translate into a high level of automation economically just as effective as is the case when the manual performance, required for the market indicated reconfiguration of the productive systems, is reduced to minimum. The solution for the "production of tomorrow" (Fig. 2) are innovative applications enabling flexible production and assembly systems, combining the advantages of production techniques based on automation and mechanization with the advantages of maximum adaptability. I.e., designed production structure enables efficient production of individual products and helps decrease the sale turbulences of the market and eliminate production dilemmas of the managers.

The customer-oriented production systems of today make their headway thank to high flexibility, based on their high-functional adaptability. These "self-optimizing systems" are able to conceive new system targets based on continuous observation of the state of the current system and to allow simultaneous adaptation of systems behaviour in synergy with new targets. They could be characterized by the following activities [10]:

$\checkmark$ "In-time" analysis of the functions the system performed.

$\checkmark$ Decision about new system targets.

$\checkmark$ Adaptation of the system to new environmental conditions.

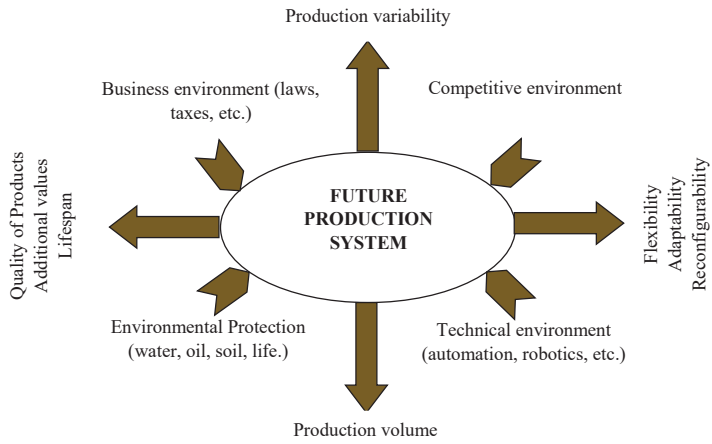

Fig. 2: Concept of adaptive modification of the production structure of the future [16].

The behaviour of these production systems is considered to be intelligent, which means they possess the ability to interact autonomously and flexibly with the environmental demand, as well as with the external users / systems or their dynamic behaviour. These systems are usually able to learn from their own experiences and are able to remember past events, which could be helpful in forecasting new events and in optimizing their behaviour under several conditions in the future based on this.

The basic pillars of creating a highly flexible system are as follows (Fig. 3) [12]:

1. Flexibility and permanent ability to provide the basis of system adaptation to dynamic factors affecting the various external stimuli resulted from environment. Flexibility could be understood as a connection between the individual parts of the system, which are predicted and defined during their planning stage. When the predicted flexibility is not sufficient for the systems feasibility under the required condition, its diversity could help reconfigure the organizational and technical parameters of the individual connections with the aim to maintain correctness and integrity.

2. Operation autonomy allows for proactive reactions to changes in the market environment. It independently guides the system to the required and safe condition during long-term operation of the same without any intervention from external operators. The higher the level of automation, the greater the likelihood of breach process. With the aim to control such breach autonomously, the integration between the components and the modules of the system, as well as the resistance to failures, must be ensured.

3. Recognition, evaluation and decision making thanks to the ability to sense the external environment. It evaluates relevant information, collects it, learns from its previous own experience to make intelligent decisions based on such information resources and to act in a safe and direct way. The decision, learning and thinking processes must be based on statistical calculations, probability analyses, available information, as well as the complex artificial intelligence tools. 


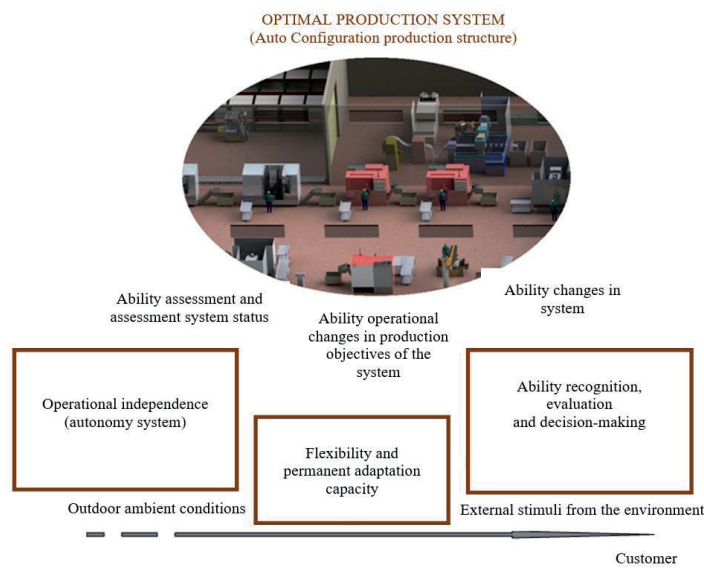

Fig. 3: Pillars of customer oriented production systems of the future [16].

The construction of production systems based on the pillars of "flexibility / diversity, autonomy, recognition ability" is possible with the help of technologies that could be synergistically functional, mutually combined. Such technology is the modularity of production technology, robotic technology with exchangeable tools and sensors, multi-sensor integration, data fusion, etc. The robotic technology, together with the standardization elements, plays the key role.

The vision of the adaptive, fast configuring production systems of the future points to subsystems of natural intelligence (the ability of recognition) which communicate together and cooperate in synergy with the predefined target functions. The key role in such systems is the permanent monitoring of the execution of the production target, with the aim of avoiding or minimizing negative effects on quality. The integration of sensing technologies and the fusion of different data sensors is necessary to ensure the quality evaluation of different products and processes. From the currently available IT technologies and hardware components point of view, this autonomous check and synchronization could be implemented to a wide range of technical options which are able to sense the environment and which are able to make decisions in a target oriented way - (MAS-multi-agent system). On the level of coordination, the responsibility for the planning and coordination of tasks is assigned, related to the final product on each decision level of the MAS. The level of planning is responsible for the planning of an optimal and economically profitable sequence of production according to the requirements on the coordination level. On the level of tasks, detailed sequence of execution of the planned tasks, together with their detailed specification and determined methodology and with the sequence for achieving the required tasks is determined. This level is responsible for functional communication between a team on the planning level and the individuals on the task level. The level of performance is responsible for direct coordination and checking of the functionality of the production technology, its elements and components (sensors, reacting members...), which are the source of important information about the current process of production, or about the final product assembly. The safety level supervises the functional integrity of all members of the system with the aim of capturing and eliminating unfavorable deviations, or "Keep them in an acceptable, feasible, qualitatively acceptable range". [10, 13]

\section{Production systems supported by design using virtual reality}

To accelerate and streamline a designer's work, a variety of tools in the classic design of production systems have already been designed and manufactured for processing especially the last stage of technological design - an image of spatial layout.

Currently, the most widely used method of technology design imaging is a two-dimensional (2D) or three-dimensional (3D) model. With 2D imaging, the individual production machines, handling, transport, storage and other devices are shown in the selected model scale based on actual ground dimensions. An important parameter is the range, the range of motion of the moving parts of the machinery, and appropriate labelling. Graphic design of production technology in three-dimensional space is made in a plane, front elevation, and side elevation. In classic design, this is a "labour intensive" activity. The front elevation always shows only one cross-section. When showing multiple cross-sections, a problem with displaying the respective relations arises.

Using 3D models is appropriate if the drawings clearly cannot define and illustrate the design section of the proposal. At the same time, the routine part of design drawings is eliminated and the 
creative aspect of the designer's work is unleashed. The 3D model of a workstation can detect collision circumstances in the primary stage of the solution that would otherwise overload the total solution due to optimizing deviations from the original state after the implementation of the selected solutions have been made and such deviations have been discovered. [14, 15]

Today, the state-of-the-art innovation trends are models of virtual reality. The aim of the virtual reality (VR) systems is to provide users or a group of users collaborating together with an illusion that they are in an artificial environment, called virtual world, virtual scene or virtual environment.

The basis for virtual reality are procedures creating spatial models and scenes where those models can be toyed with, moved in three-dimensional space and displayed in real time. Using special peripherals to deliver video, audio and tactile interactions, virtual reality brings extraordinary experiences and brings about new and unexpected possibilities to computer technology applications. Virtual reality applications have the following characteristics [16]:

\section{$\checkmark$ Actions occur in real time.}

$\checkmark$ Scenes and objects are three-dimensional or create an illusion of being so.

$\checkmark$ The user can enter the scene and move through it.

$\checkmark$ The scene is not static; the user can interact with its objects.

Virtual Reality enhances the distribution of imaging techniques in computer graphics in two ways. The first aim is rapid creation of an image and the second objective is to create a realistically looking object.

Modeling and 3D imaging is an irreplaceable area of design dealing with the creation of production systems and with their implementation into nowadays largely utilized CAD systems. The computer graphics is the basis for virtual reality processes, namely for creation of spatial models and scenes, interacting with them, moving in three-dimensional space, detecting collisions and real-time display. These methods are enhanced by the use of peripherals that provide video, audio and tactile interaction. In particular, these are the helmets with built-in screens, stereoscopic projection screens, position sensors in space, tactile devices, simulation cabins, etc.

Virtual reality models allow to:

$\checkmark$ replace physical prototypes with virtual ones,

$\checkmark$ simulate various stages of development in virtual environment, $\checkmark$ improve and accelerate the product development and other processes, etc.

The purpose of virtual reality is that the virtual environment can be shared by many users at once, and allows them to interact with each other. In this way, several people can work together to solve problems. [17]

Examples of three-dimensional models that were created in the environment of the Autodesk Inventor graphic system are shown below (Fig. 4, 5). The primary source of information were drawings, brochures and catalogues of manufacturing technology. Application program systems using advanced computer graphics are strongly supported by information databases. These may include elementary geometric 2D or 3D objects in their structures, from which individual facilities of manufacturing technology are modelled, or contain reliable, previously created models of these facilities. For trustworthy records of the models, basic methods derived from principles of computer graphics were used. Each model is a 3D model of a production facility at 1:1 scale. A file of graphical information about devices is recorded in the socalled information sheet.
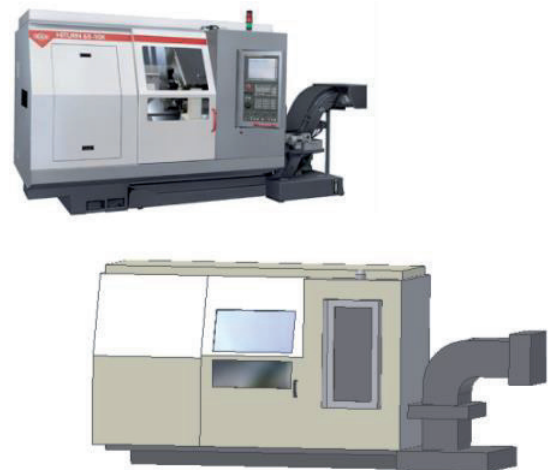

Fig. 4: Examples of information sheet extracted from the database of manufacturing technical models.

Following the successful introduction of 3D model of a production facility into a database, it is possible to search and select appropriate equipment for the production system design. The user will search for the required model by defining the parameter as a specified criterion or by selecting it from the list of models (Module database is marked "PDM integrator") that the database includes.

Methodology for designing a new production cluster using this module starts with the choice of 


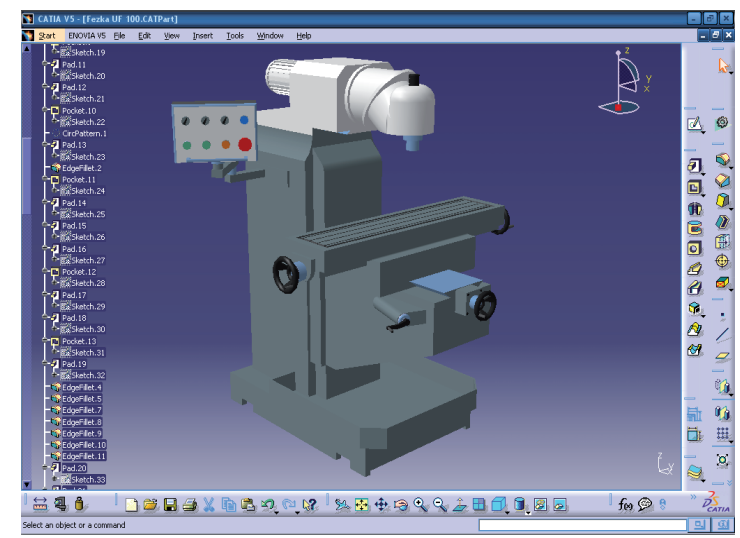

Fig. 5: Example of 3-dimensional model of production equipment created in a CAD system.

the design area.

Models of production equipment are selected from the database and situated on the selected design area that was created as a *ipt component and stored in the database. Models of manufacturing clusters are created by the user - designer, using information from the production facilities database in the desired output format in 3-dimensional or 2-dimensional space (assembly *iam). Method for selecting an area for designing manufacturing equipment is in Fig. 6.

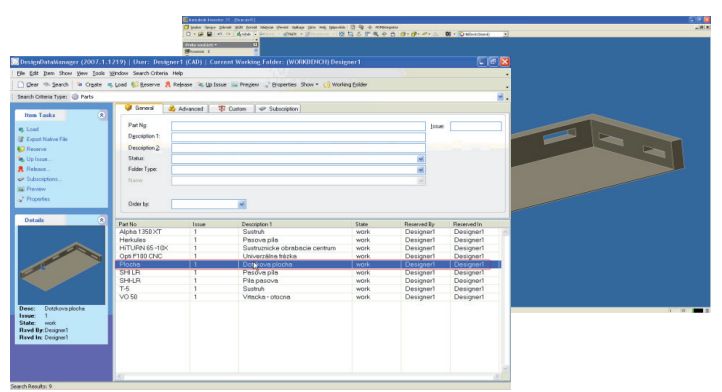

Fig. 6: Method for selecting an area for designing manufacturing equipment.

Individual models inserted in the configuration will be connected (command "joining") in the final alignment and, depending on the proposal, their deployment will be adjusted to achieve the desired position, which determines the final alignment of the production system model. The final alignment of a production cluster is in Fig. 7.

Fig. 8 shows the model of a production system from a different point of view. Using the resources of virtual reality, realistic scenes can be created in 3D environment, to be used for practical purposes in further product development and testing and even in training of workers and maintenance personnel who will manufacture the product and operate the equipment in the future.

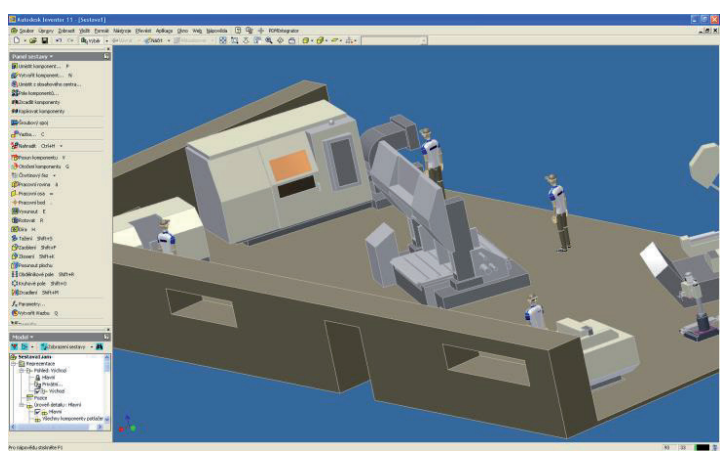

Fig. 7: The final alignment of a production cluster.

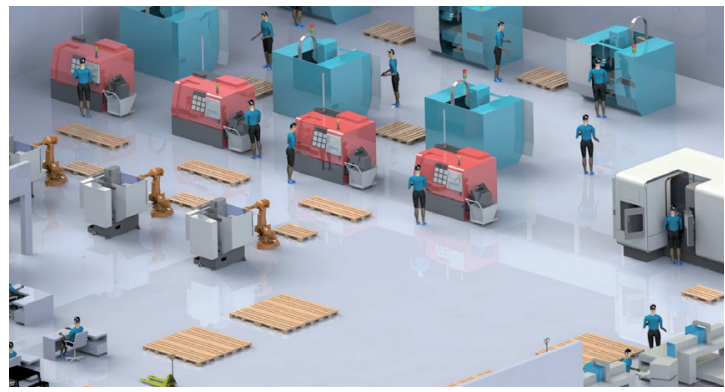

Fig. 8: Production system model.

\section{Conclusions}

Currently, production companies face global competition caused by more demanding customers. Therefore, companies seek to make their activities more efficient in the so-called supply chain environment. They join the production structure network, which means that suppliers and customers become part of those production structures. Such systems need not only to be managed but also to optimize their activity based on appropriate criteria. Development of new information technology enables the use of network (computer) communication structures for the transfer and management of information flows, the management of material and financial flows, and for finding optimal conditions for a company's production based on customer requirements. [18]

Program modules of advanced graphic systems rely on significant support from information databases that contain either elementary 3D objects for technical execution modeling in their structure 
or reliable models created in advance.

In this time, many companies use a twodimensional (2D) or three-dimensional (3D) modelling and it can be said that it will not change in the near future. Because of that fact, it will be crucial for every company to adopt on this fact and to make decisions that will enable them to be more competitive on the market.

Virtual Reality is in our opinion the only possible and effective way for designing the production system structures in the next years, because we don't have better and cheaper way to view production system structure before we spend money for their realization in the practice.

\section{Acknowledgments}

This article was created by implementation of the project KEGA 030TUKE-4/2017 "Implementation of innovative instruments for increasing the quality of higher education in the 5.2.52 Industrial Engineering field of study". This publication was supported by the Operational Program Research and Innovation for the project: The Research of New-Generation Materials, Structures, and Technologies in the Industrial Production of the 215t Century, NFP313011T594, co-financed by the European Union from the European Regional Development Fund.

\section{References and Notes}

[1] Bracht, U., Geckler, D., Wenzel, S. (2011). Digitale Fabrik Methoden und Praxisbeispiele. Springer, ISBN 978-3-54089038-6

[2] Bubeník, P., Bubeníková, E., Korbel, P., Nagy, P. (2004). Information Technology for Business Practice. Edis, ŽU in Žilina.

[3] Buda, J., Kováč, M. (1990). Design and operation of robotic systems. Alfa Bratislava.

[4] Groover, M., P.: Automation, Production Systems and Computer - Integrated manufacturing. Second Edition Printice Hall International, Inc.

[5] https://www.vdi.de/nc/richtlinie/vdi_4499_blatt_1digitale_fabrik_grundlagen/

[6] Kersten, W., Koller, H., Lödding, H. (2014). Industrie 4.0. Wie intelligente Vernetzung und kognitive Systeme unsere Arbeit verändern. GITO mbH Verlag Berlin

[7] Kovač J., Rudy V., Kováč Ju. (2017). Methods for the design of production processes. Specifics of designing production systems. Edition of professional and scientific literature. SjF TU in Košice

[8] Kováč, J., Rudy, V., Kováč, Ju. (2016). Automation of production. Edition of scientific and professional literature. SjF TU in Košice.
[9] Kováč, J., Rudy, V., Kováč, Ju. (2017). Production Process Design Methodology 1. Specifics of Production Process Design. Košice. SjF TU in Košice

[10] Kováč, J., Rudy, V., Mareš, A., Kováč, Ju., Malega, P. (2012). Integrated designing of production systems on the physical and virtual modelling base. In: Acta Mechanica Slovaca. Vol. 16 , No. 1, p. 30-40

[11] Kováč, M., Kováč, J. (2011). Innovative design of production processes and systems. SjF TU in Košice

[12] Kühn, W. (2006). Digitale Fabrik. Fabriksimulation für Produktionsplaner. Carl Hanser Verlag München, Wien

[13] Malega, P., Kováč, J. (2016). Design of Assembly System Mixed Reality Modelling. In: DAAAM 2016. p. 289-297.

[14] Mareš, A. (2006). Techniques for shortening the time of design of assembly processes and systems. Diz. work. SjF TU in Košice

[15] Mičieta, B., Edl, M., Krajčovič, M., Dulina, L., Bubeník, P., Ďurica, L., Biňasová, V. (2018). Delegate MASs for coordination and control of one-directional AGV systems: a proof-of-concept. In: The International Journal of Advanced Manufacturing Technology. Berlin: Springer. Vol. 94, No. 1-4, p. 415-431

[16] Modrák, V. (2001). Contribution to Designing Structural Changes in Manufacturing Processes. Hab. work, FTT TU in Košice

[17] Scheer, A., W. (1994). CIM Computer Integrated Manufacturing. Towards the Factory of the Future. Third, Revised and Enlarged Edition. Springer-Verlag, Berlin Heidelberg

[18] Wiendahl, H., P., Reichardt, J., Nyhuis, P. (2015). Handbook Factory Planing. Springer-Verlag Berlin Heidelberg

[19] Kmec, J., Valenčík, Š., Gombár, M., Karková, M., Vagaská, A. (2016). Logistic Approach of Building and Development of Production Systems. In: Nase More. Vol. 63, No. 3, p. 145-149

[20] Cochran, D. S., Eversheim, W., Kubin, G., Sesterhenn, M. L. (2000). The Application of Axiomatic Design and Lean Management Principles in the Scope of Production System Segmentation. In: International Journal of Production Research. Vol. 38, No. 6, p. 1377-1396

[21] Manzini, M., Unglert, J., Gyulai, D., Colledani, M., JaureguiBecker, J. M., Monostori, L., Urgo, M. (2018). An integrated framework for design, management and operation of reconfigurable assembly systems. In: Omega - International journal of management science. Vol. 78, Special Issue, p. 6984 